\title{
THE OCCURRENCE AND SOURCE EVALUATION OF POLYCYCLIC AROMATIC HYDROCARBONS IN URBAN ATMOSPHERE USING MOSS AS BIOMONITOR AND GC-MS ANALYSIS
}

\section{ANDREEA ROTARU ${ }^{a}$, EDINA REIZER ${ }^{a}, V_{L A D}$ PĂNESCU ${ }^{a}$, SORIN POP ${ }^{a}$, MIHAIL SIMION BELDEAN-GALEA ${ }^{a^{*}}$}

\begin{abstract}
Polycyclic aromatic hydrocarbons (PAHs) make part of the persistent organic pollutants (POPs) class. The most harmful PAHs are generated during the incomplete combustion of organic material. European legislation has recommended the use of bioindicators to estimate the impact of PAHs on the ecosystem. The aim of this work was to investigate the occurrence of atmospheric PAHs in 14 urban areas in Romania, using moss as bioindicator. The pollution emission sources, applying diagnostic ratios, were also evaluated. The PAHs were analyzed by gas chromatographymass spectrometry (GS-MS). This study showed the presence of PAHs in moss samples in concentrations which are dependent on the sampling zone, ranging from 2.7 to $394 \mathrm{ng} \mathrm{g}^{-1}$. The cities with the highest amounts of total PAHs were found within the Carpathian arch, while the cities situated in the western part of the country had the lowest amounts. The FLA/(FLA+PYR) and FL/(FL+PYR) ratios indicate both the diesel emission source, fossil fuels combustion source and wood or coal combustion source which may come either from traffic, industrial activities, centralized heating systems, or from other type of industry.
\end{abstract}

Keywords: Polycyclic aromatic hydrocarbons, urban atmosphere, bioindicators, moss, GC-MS

\footnotetext{
a Babeş-Bolyai University, Faculty of Environmental Science and Engineering, 30 Fântânele street, RO-400294, Cluj-Napoca, Romania

Corresponding author simion.beldean@yahoo.com
} 


\section{INTRODUCTION}

Polycyclic aromatic hydrocarbons (PAHs) make part of the persistent organic pollutants (POPs) class, having a structure composed of multiple aromatic rings. In 1976, the U. S. Environmental Protection Agency (U.S. EPA) reduced the group of hundreds of PAHs to only 16 relevant compounds [1-2], issuing a list with "16 priority PAHs" to be representative for all. Furthermore the 16 EPA PAHs became crucial subjects for environmental examinations.

The most harmful PAHs are generated during the incomplete combustion of organic material, predominantly due to anthropogenic activities [3]. In highly populated and heavily urbanized or industrialized areas, the most significant emission sources are residential heating, coal gasification, asphalt production, and motor vehicle exhaust [4]. In order to identify and assess the source of PAHs, numerous studies have been published most of them based on different diagnostic ratios [5-8].

Environmental assessment of PAHs in ambient air is essential, because many of them exhibit carcinogenic and mutagenic properties [9]. PAHs are omnipresent in two phases in the lower atmosphere with different concentration levels: in vaporous phase and in solid phase as sorbet onto aerosols [10]. After their atmospheric transportation and dry or wet deposition, processes that are strongly dependent on the relationship between vapor pressure and molecular weight [11], PAHs tend to accumulate in vegetation. Biomonitoring of PAHs on plants gained popularity in the last four decades [12-15]. The application of moss as passive accumulator for PAHs is widespread in so-called air quality assessment studies, because of (i) their strong presence at the local scale, (ii) their relative cost-effective methodology (compared to physicalchemical approach) [15], (iii) their morphological and physiological properties [16-17].

In addition, European legislation has recommended the use of bioindicators to estimate the impact of PAHs on the ecosystem [18]. Directive 2004/107/EC of the European Parliament granted the Member State the employment of any other sampling methods to assess spatial deposition of PAHs, with which they can demonstrate that the results are equivalent to those obtained with reference methods, such as: ISO standard 12884:2000.

The aim of this work was to investigate the occurrence of atmospheric PAHs in 14 urban areas in Romania, using moss as bioindicator and to establish the pollution emission sources, applying different diagnostic ratios. 
THE OCCURRENCE AND SOURCE EVALUATION OF POLYCYCLIC AROMATIC HYDROCARBONS ...

\section{RESULTS AND DISCUSSION}

\subsection{Analytical performance of the analysis method}

Precision, linearity, limit of detection (LOD) and limit of quantification (LOQ) (Table 1) were the variables taken into account to study the performance of the GC-MS method used for the analysis of PAHs in moss samples.

Table 1. Analytical performances of GC-MS method

\begin{tabular}{|c|c|c|c|c|c|c|c|}
\hline Compound & $\begin{array}{c}\text { Linear curve } \\
\text { equation (range } \\
\left.0.04-2 \mu \mathrm{g} \mathrm{m}^{-1}\right)\end{array}$ & $\mathrm{R}^{2}$ & Slope & SD & $\begin{array}{c}\text { LOD } \\
\left(\mu \mathrm{g} \mathrm{mL}^{-1}\right.\end{array}$ & $\left(\begin{array}{c}\mathrm{LOQ} \\
\left(\mu \mathrm{g} \mathrm{mL}^{-1}\right)\end{array}\right.$ & $\begin{array}{c}\mathrm{RSD} \\
\%\end{array}$ \\
\hline Naphthalene & $\begin{array}{c}y=104860236 x \\
+14714750\end{array}$ & 0.994 & 104860236 & 208708 & 0.006 & 0.020 & 3.26 \\
\hline Acenaphthylene & $y=86128700 x+$ & 0.992 & 86128700 & 213042 & 0.007 & 0.025 & 4.35 \\
\hline Acenaphthene & $y=29620687 x+$ & 0.992 & 29620687 & 76969 & 0.008 & 0.026 & 4.07 \\
\hline Fluorene & $y=53467933 x+$ & 0.991 & 53467933 & 90371 & 0.005 & 0.017 & 2.93 \\
\hline Phenanthrene & $\begin{array}{c}y=57418106 x+ \\
8784001\end{array}$ & 0.992 & 57418106 & 164470 & 0.009 & 0.029 & 3.49 \\
\hline Anthracene & $y=65827841 x+$ & 0.981 & 65827841 & 146115 & 0.007 & 0.022 & 3.54 \\
\hline Fluoranthen & $\begin{array}{c}y=52675476 x+ \\
9097934\end{array}$ & 0.985 & 52675476 & 114724 & 0.007 & 0.022 & 3.31 \\
\hline Pyrene & $\begin{array}{c}y=52161938 x+ \\
9634681\end{array}$ & 0.982 & 52161938 & 105882 & 0.006 & 0.020 & 3.00 \\
\hline Benz[a]anthracene & $\begin{array}{c}y=30467866 x+ \\
5076543\end{array}$ & 0.976 & 30467866 & 48552 & 0.005 & 0.016 & 2.36 \\
\hline Chrysene & $y=\begin{array}{c}30795452 x+ \\
7611809\end{array}$ & 0.957 & 30795452 & 59244 & 0.006 & 0.019 & 2.37 \\
\hline Benzo[b]fluoranthene & $\begin{array}{c}\mathrm{y}=22969230 \mathrm{x}+ \\
3977709\end{array}$ & 0.973 & 22969230 & 61071 & 0.008 & 0.027 & 3.43 \\
\hline Benzo[k]fluoranthene & $y=23772068 x+$ & 0.951 & 23772068 & 41801 & 0.005 & 0.018 & 2.11 \\
\hline Benzo[a]pyrene & $\begin{array}{c}y=21785791 x+ \\
4918591\end{array}$ & 0.954 & 21785791 & 33623 & 0.005 & 0.015 & 1.84 \\
\hline $\begin{array}{l}\text { Indeno(1.2.3 } \\
\text { cd)pyrene }\end{array}$ & $\begin{array}{c}y=14855868 x+ \\
3799708\end{array}$ & 0.946 & 14855868 & 71739 & 0.014 & 0.048 & 5.06 \\
\hline Dibenz[a.h]anthracene & $y=18949082 x+$ & 0.929 & 18949082 & 152213 & 0.024 & 0.080 & 6.62 \\
\hline Benzo[ghi]perylene & $y=16697664 x+$ & 0.928 & 16697664 & 79739 & 0.014 & 0.048 & 4.12 \\
\hline
\end{tabular}

$\mathrm{R}^{2}$ - coefficient of determination; SD - standard deviation; LOD - limit of detection, LOQ - limit of quantification, RSD - relative standard deviation for $(n=6)$; 
Intra-day precision (repeatability) was expressed by means of six replicates $(n=6)$ of a 16 PAHs standard mixture in concentration of 0.04 $\mu \mathrm{g} \mathrm{mL}^{-1}$. The obtained results were situated under $15 \%$, ranging between $1.84 \%$ and $6.62 \%$, which prove a good repeatability of the method.

Calibration curve method was used to quantify the target compounds in real samples. In Table 1 one may observe a good linearity for all target PAHs, $R^{2}$ values ranging from 0.928 to 0.994 . LOD and LOQ of each of the $\mathrm{PAHs}$ were determined using the standard deviation and the slope of each calibration curve. LODs and LOQs were situated in the range of 0.005 and $0.024 \mu \mathrm{gL}^{-1}$, and between 0.016 and $0.08 \mu \mathrm{g} \mathrm{mL}^{-1}$, respectively.

\subsection{Analysis of moss samples}

The presence of multiple PAHs in moss samples collected from various central parks from some of Romania's largest cities is demonstrated in all analyzed samples. In Figure 1 it is shown an integrated chromatogram of an extract of mosses collected from Copou Park, lași city, where the presence of PAHs can be observed.

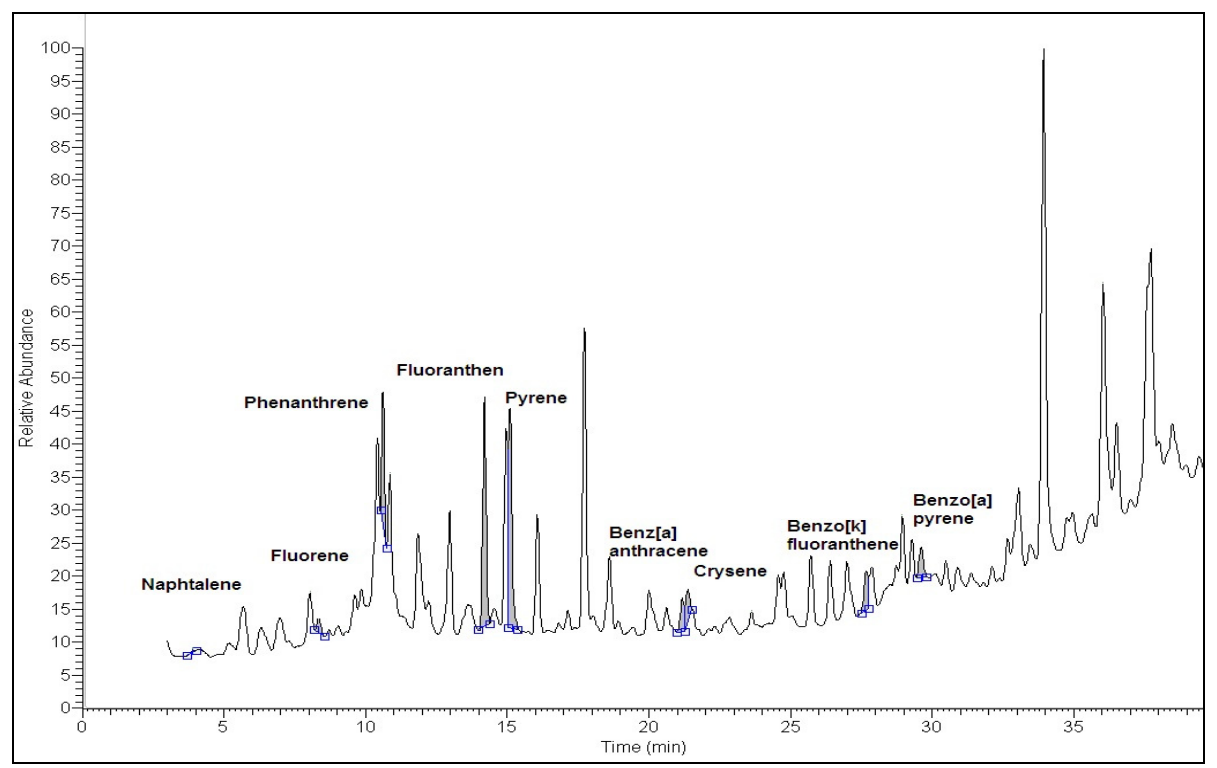

Figure 1. SIM Chromatogram of tested PAHs in moss sample (lași city)

The content of PAHs in the analyzed moss samples collected from the selected sampling areas is shown in Table 3. 
THE OCCURRENCE AND SOURCE EVALUATION OF POLYCYCLIC AROMATIC HYDROCARBONS ...

Table 3. The occurrence of PAHs in analyzed moss samples

\begin{tabular}{|c|c|c|c|c|c|c|c|c|c|c|c|c|c|c|c|}
\hline \multirow[b]{2}{*}{ Compound } & \multicolumn{15}{|c|}{ Sample code/Concentration $\left(\mathrm{ng} \mathrm{g}^{-1}\right)$} \\
\hline & Abb. & S1 & S2 & S3 & S4 & S5 & S6 & S7 & S8 & s9 & $\mathrm{S} 10$ & S11 & $\mathrm{S} 12$ & $\mathrm{~S} 13$ & S14 \\
\hline Naphthalene & NP & 0.87 & nd & 0.06 & 16.42 & nd & 3.9 & 1.95 & nd & 0.76 & 2.44 & 0 & 0 & nd & nd \\
\hline Acenaphthylene & $A C Y$ & 1.38 & nd & nd & 97.43 & 8.85 & nd & 3.59 & 2.28 & 3.5 & 1.81 & 4.12 & 4.62 & nd & 2.79 \\
\hline Acenaphthene & ACE & nd & nd & nd & 34.24 & 2.71 & nd & 1.92 & nd & 1.54 & nd & nd & nd & nd & 2.35 \\
\hline Fluorene & $\mathrm{FL}$ & 1.1 & 2.36 & 1.26 & 5.95 & 5.31 & nd & nd & nd & 8.81 & nd & nd & 10.09 & nd & 2.68 \\
\hline Phenanthrene & PHE & 1.57 & 0.98 & 6.69 & 12.84 & 21.15 & 17.17 & 9.33 & 1.79 & 2.54 & 4.92 & 4.14 & 1.87 & nd & 10.14 \\
\hline Anthracene & ANT & nd & nd & nd & nd & nd & nd & nd & nd & nd & nd & nd & nd & 1.59 & 50.46 \\
\hline Fluoranthene & FLA & 2.73 & 1.39 & 19.41 & 33.47 & 28.74 & 16.26 & 13.27 & 8.47 & 5.98 & 8.28 & 2.66 & 6.38 & nd & 3.15 \\
\hline Pyrene & PYR & 0.91 & nd & 18.83 & nd & 14.6 & 11.06 & 11.57 & 4.85 & 4.74 & 11.02 & 2.62 & 5.22 & 1.13 & 5.78 \\
\hline $\begin{array}{l}\text { Benz[a]anthra } \\
\text { cene }\end{array}$ & $\mathrm{BaA}$ & 0.67 & 0.18 & 7.2 & 5.7 & 1.33 & 0.3 & 0.84 & 15.85 & 1.08 & 0.44 & 0.68 & 0.54 & nd & 0.98 \\
\hline Chrysene & CHR & nd & 0.02 & 5.11 & nd & nd & nd & nd & nd & nd & nd & nd & nd & nd & nd \\
\hline $\begin{array}{l}\text { Benzo[b]fluoran } \\
\text { thene }\end{array}$ & $\mathrm{BbF}$ & nd & nd & nd & 4.93 & nd & nd & nd & nd & nd & nd & 1.81 & nd & nd & nd \\
\hline $\begin{array}{l}\text { Benzol[k]fluoran } \\
\text { thene }\end{array}$ & $\mathrm{BkF}$ & nd & nd & 12.89 & 23.75 & nd & nd & nd & nd & nd & nd & nd & nd & nd & 88.01 \\
\hline Benzo[a]pyrene & $\mathrm{BaP}$ & 2.4 & 6.56 & 10.81 & 8.65 & 54.77 & 10.39 & 9.76 & 8.43 & 15.73 & 4.04 & 8.14 & 5.71 & nd & 2.53 \\
\hline $\begin{array}{l}\text { Indeno(1,2,3- } \\
\text { cd)pyrene }\end{array}$ & IcdP & 344.9 & 156.8 & nd & nd & nd & nd & nd & nd & nd & nd & nd & nd & nd & 206.3 \\
\hline $\begin{array}{l}\text { Dibenz[a,h]anth } \\
\text { racene }\end{array}$ & DahA & nd & 4.94 & nd & nd & nd & nd & nd & nd & nd & nd & nd & nd & nd & 16 \\
\hline $\begin{array}{l}\text { Benzo[ghi]peryle } \\
\text { ne }\end{array}$ & Bghip & 2.49 & nd & nd & nd & nd & nd & nd & 3.59 & nd & nd & nd & nd & nd & 2.81 \\
\hline Total PAHs & & 359 & 173.3 & 82.3 & 243.4 & 137.5 & 59.1 & 52.2 & 45.3 & 44.7 & 33 & 24.2 & 34.4 & 2.7 & 394 \\
\hline
\end{tabular}

nd- not detected

The results of the analyzed moss samples showed that, the cities with highest amounts of $\Sigma$ PAHs were found within the Carpathian arch. The highest amount of $\Sigma$ PAHs, $394 \mathrm{ng} \mathrm{g}^{-1}$ was found in Cluj-Napoca city (S14), followed by Alba lulia city (S1), with $359 \mathrm{ng} \mathrm{g}^{-1}$ and Brașov city (S4), with $243 \mathrm{ng} \mathrm{g}^{-1}$, Sibiu city (S2), with $173.3 \mathrm{ng} \mathrm{g}^{-1}$, Bistrița city (S5), with $137.5 \mathrm{ng}$ $\mathrm{g}^{-1}$, and Târgu Mureș city with $45.3 \mathrm{ng} \mathrm{g}^{-1}$ 
The cities situated in the western part of the country had the lowest amounts, below $40 \mathrm{ng} \mathrm{g}^{-1}$, top of which, with $2.7 \mathrm{ng} \mathrm{g}^{-1}$ was Timișoara city (S13), followed by Arad city (S11), with $24.2 \mathrm{ng} \mathrm{g}^{-1}$, and Oradea city (S12), with $34.4 \mathrm{ng} \mathrm{g}^{-1}$, although Poiești city, situated in the southern part of Romania had a slighter smaller amount, of $33 \mathrm{ng} \mathrm{g}^{-1}$.

The cities situated in the eastern part of the country have slightly higher concentrations of PAHs in moss samples than those situated in the southern part, with $52.2 \mathrm{ng} \mathrm{g}^{-1}$ in Bacău city (S7) and $82.7 \mathrm{ng} \mathrm{g}^{-1}$ in lași city (S3). The south of the country had values between $33 \mathrm{ng} \mathrm{g}^{-1}$ in Ploiești city (S10), $59 \mathrm{ng}$ $\mathrm{g}^{-1}$ in Pitești city (S6) and $44.7 \mathrm{ng} \mathrm{g}^{-1}$ in Bucharest (S9), the country's capital.

\subsection{PAHs sources identification using isomeric ratios}

To establish the source of the analyzed PAHs, several isomeric ratios were used such as: $\Sigma$ sum of Low Molecular Weight PAHs (two-three ring PAHs) and $\Sigma$ sum of High Molecular Weight PAHs (four-six rings PAHs) ratio $\left(\sum_{L M W} / \sum_{H M W}\right)$; sum of PAH resulted from combustion (FLA, PYR, BaA, CHR, $\mathrm{BkF}, \mathrm{BbF}, \mathrm{BaP}$, IcdP and BghiP) and sum of total PAHs $\left(\Sigma_{\mathrm{COMB}} / \Sigma_{\mathrm{PAHs}}\right)$, the $\mathrm{FL} /(\mathrm{FL}+\mathrm{PYR})$ and $\mathrm{FLA} /(\mathrm{FLA}+\mathrm{PYR})$ ratios [19]. As one may observe in Table 3, the $\sum_{\llcorner M W} / \sum_{\text {HMW }}$ ratio indicates that there is a pyrogenic source in all the samples, except Brașov city (S4) the obtained values being situated under 1 value. The $\Sigma_{\text {COMB }} / \Sigma_{\text {PAHs }}$ ratio indicates a combustion source $(\sim 1)$ in most of the cities, except Brașov city (S4), Oradea city (S12) and Timișoara city (S13) of which the values are far away from 1 . The $F L /(F L+P Y R)$ ratio indicates a petrol emission in Alba lulia city (S1), București city (S9) and Oradea city (S12) (values under 0.5), and a diesel emission in lași city (S3), Bistrița city (S5) and Cluj-Napoca city (S14) (values over 0.5). Finally, the FLA/(FLA+PYR) ratio, indicates petrogenic source in Cluj-Napoca city (S14) (value under 0.4), fossil fuel combustion source in Ploiești city (S10) (value between 0.4 and 0.5 ), and grass, wood or coal combustion source (value over 0.5 ) in all the other cities that could have this ratio calculated.

Table 3. Available PAH diagnostic ratios according to sampling locations

\begin{tabular}{|c|c|c|c|c|c|c|c|c|c|c|c|c|c|c|}
\hline & $\mathrm{S} 1$ & $\mathrm{~S} 2$ & S3 & S4 & S5 & $\mathrm{S} 6$ & S7 & $\mathrm{S} 8$ & S9 & $\mathrm{S} 10$ & S11 & $\mathrm{S} 12$ & $\mathrm{~S} 13$ & $\mathrm{~S} 14$ \\
\hline$\Sigma_{\text {LMW }} / \Sigma_{\text {HMW }}$ & 0.01 & 0.01 & 0.02 & 1.72 & 0.14 & 0.07 & 0.17 & 0.05 & 0.49 & 0.15 & 0.21 & 0.75 & NA & 0.02 \\
\hline$\Sigma_{\mathrm{COMB}} / \Sigma_{\mathrm{PAH}} \mathrm{S}$ & 0.99 & 0.95 & 0.9 & 0.31 & 0.72 & 0.64 & 0.68 & 0.91 & 0.62 & 0.72 & 0.66 & 0.52 & 0.42 & 0.79 \\
\hline $\mathrm{FL} /(\mathrm{FL}+\mathrm{PYR})$ & 0.55 & NA & 0.06 & NA & 0.27 & NA & NA & NA & 0.65 & NA & NA & 0.66 & NA & 0.32 \\
\hline $\mathrm{FLA} /(\mathrm{FLA}+\mathrm{PYR})$ & 0.75 & NA & 0.51 & NA & 0.66 & 0.6 & 0.53 & 0.64 & 0.56 & 0.43 & 0.5 & 0.55 & NA & 0.35 \\
\hline
\end{tabular}

If the sources according to the FLA/(FLA+PYR) and FL/(FL+PYR) ratios are cross-examined (Figure 2), one may observe that mixed sources of 
$\mathrm{PAH}$ are present in all studied areas. Thus, in Cluj-Napoca (S14) there is a petrogenic and petrol emission source, which is probably due to vehicle emissions. In Alba lulia city (S1), București city (S9) and Oradea city (S12) the sources are both from diesel emission and from wood or coal combustion. These ratios indicate both heavy traffic (the diesel emission source) and industrial activities (wood or coal combustion source - either from the centralized heating systems or from other type of industries). In lași city (S3) and Bistrița city (S5) the sources are both from petrol and from wood or coal combustion. Bistrița city seems to be more inclined towards industry, while lași city tends to have a more likely fossil fuels combustion source.

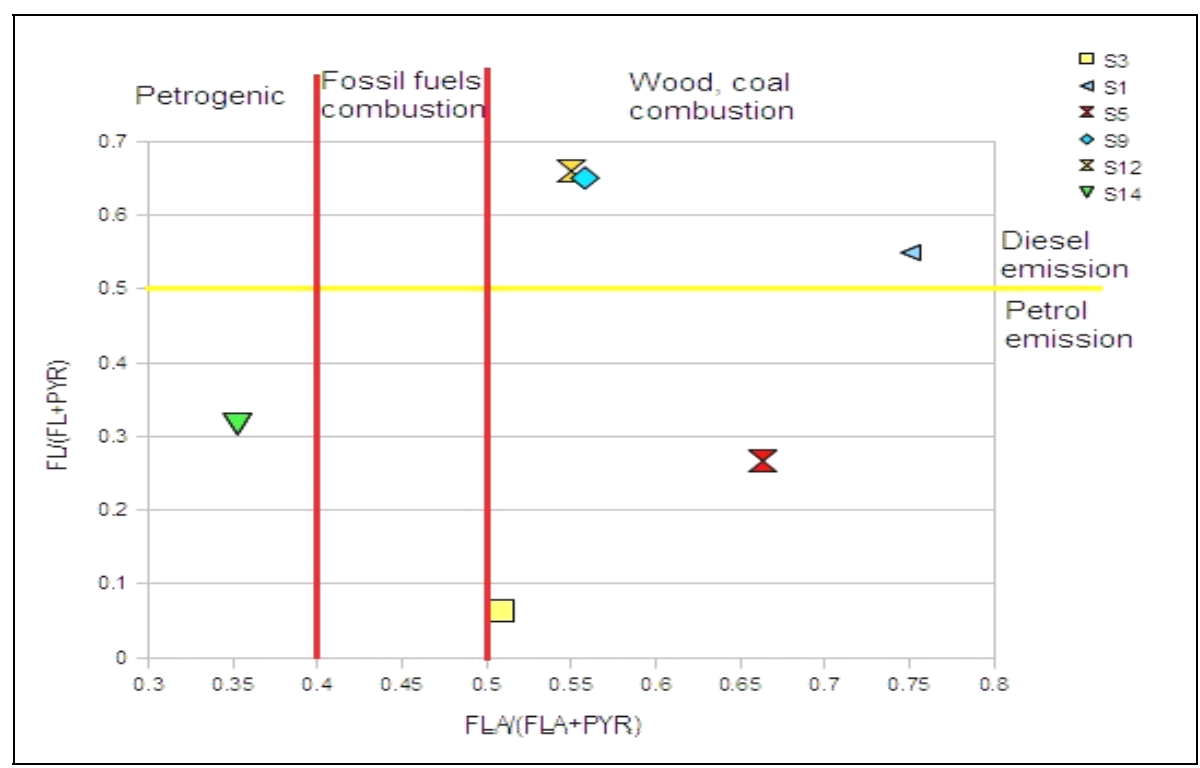

Figure 2. Cross examination of the FLA/ (FLA+PYR) against FL/ (FL+PYR) ratios in the selected locations

\section{CONCLUSIONS}

This study showed the presence of PAHs in moss samples in concentrations which are dependent on the sampling zone.

The cities with the highest amounts of $\Sigma \mathrm{PAHs}$ were found within the Carpathian arch, while the cities situated in the western part of the country had the lowest amounts. The cities located in the estern part of the country have slightly higher concentrations of PAHs in moss samples than those situated in the southern part. 
The $\sum_{\mathrm{LMW}} / \sum_{\mathrm{HMW}}$ ratio indicates that there is a pyrogenic source in all the samples, and the $\sum_{\text {comB }} / \sum_{\text {PAHs }}$ ratio confirms the combustion source $(\sim 1)$ in most of the cities.

The $F L A /(F L A+P Y R)$ and $F L /(F L+P Y R)$ ratios indicate both heavy traffic (the diesel emission source and fossil fuels combustion source) and industrial activities (wood or coal combustion source), which may come either from the centralized heating systems, or from other type of industries.

\section{EXPERIMENTAL SECTION}

\subsection{Reagents and solutions}

For the qualitative and quantitative analysis an EPA PAH standard mixture containing 16 compounds in concentration of $2 \mu \mathrm{g} \mathrm{mL} \mathrm{m}^{-1}$ of each compound purchased by Supelco was used. The PAHs determined were: naphthalene, acenaphthene, acenaphtylene, fluorene, phenanthrene, anthracene, fluoranthene, pyrene, benz[a]anthracene, chrysene, benzo[b]fluoranthene, benzo[k]fluoranthene, benzo[a]pyrene, indeno(1,2,3cd)pyrene, dibenz[ah]anthracene and benzo[ghi]perylene. Dichloromethane and n-hexane in purity of $99.99 \%$ were purchase from Merck, Germany and helium in purity of $99.9999 \%$ from Linde Gas, Romania.

\subsection{Instrumentation and chromatographic conditions}

The PAHs were analyzed by gas chromatography-mass spectrometry using a gas chromatograph model Thermo Electron Corporation (Focus GC) equipped with a DSQII mas spectrometer and a TriPlus Autosampler. The separation of target compounds was performed on DB-5 MS column (25 m $x 0.25 \mathrm{~mm} \times 0.25 \mu \mathrm{m}$ ) using helium as carrier gas at a constant flow of $1,2 \mathrm{~mL}$ $\min \neg 1$. The MS ion source was heated at $200^{\circ} \mathrm{C}$, and the detection of the target compounds was made on selected ion monitoring (SIM) mode.

The separation of the PAHs was performed with two gradient of temperature as follows: from $120^{\circ} \mathrm{C}$, up to $220^{\circ} \mathrm{C}$ with $10^{\circ} \mathrm{C}$ min $\neg 1$, and from $220^{\circ} \mathrm{C}$ to $300^{\circ} \mathrm{C}$ with $3^{\circ} \mathrm{C}$ min 1 . Injection volume was $1 \mu \mathrm{L}$ in splitless mode.

The quantification of the target compounds in real samples was made by the calibration curve method. For this purpose five standard solutions in concentration of $0.04,0.05,0.07,0.1$ and $0.2 \mu \mathrm{g} \mathrm{mL}^{-1}$ were prepared by dilution of the standard mixture $\left(2 \mu \mathrm{g} \mathrm{mL}^{-1}\right)$. The calibration curves were built using the chromatographic peak area and the concentration of each of the PAHs. 


\subsection{Ultrasound assisted extraction procedure}

From each sample, $3 \mathrm{~g}$ of milled moss were weighed in a Berzelius beaker then added thirty milliliter of a mixture of $n$-hexane:dichloromethane $(1: 1 \mathrm{v} / \mathrm{V})$. The samples were placed in ultrasonic bath for 15 minutes and then the solvent was decanted and filtered through a PVDF sample filter with pore size of $0.45 \mu \mathrm{m}$ (Merck Milipore). The resulted extract was evaporated to dryness with a rota-evaporator and the residue was dissolved with 2 milliliter of $n$-hexane:dichloromethane $(1: 1 \mathrm{v} / \mathrm{v})$ mixture and kept in the freezer until the analysis.

\subsection{Sampling points}

The study was carried out in 14 of the largest cities in Romania (Figure 3). All of the samples were collected at distances of more than $5 \mathrm{~m}$ from roads and houses, from 1 - 2 meters high. The samples were all collected from central parks areas.

The moss samples were collected with a stainless steel scissors in sterilized polyethylene bags and kept at $8^{\circ} \mathrm{C}$ until analysis.

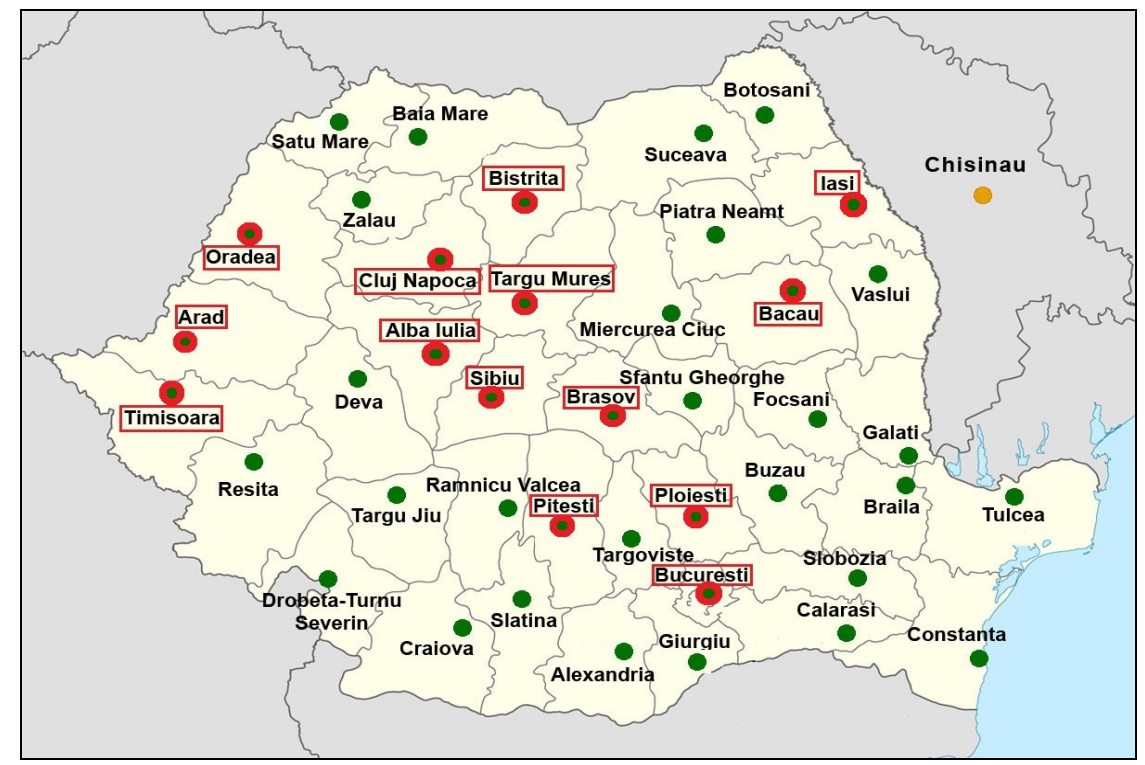

Figure 3. The map of moss sampling points (Alba lulia city (S1), Sibiu city (S2), lași city (S3), Brașov city (S4), Bistrița city (S5), Pitești city (S6), Bacău city (S7), Târgu Mureș city (S8), Bucharest (S9), Ploiești city (S10), Arad city (S11), Oradea city (S12), Timișoara city (S13), Cluj-Napoca city (S14)) 
A. ROTARU, E. REIZER, V. PĂNESCU, S. POP, M. S. BELDEAN-GALEA

\section{ACKNOWLEDGEMENTS}

This study was performed in the frame of a performance scholarship funded by Babeş-Bolyai University.

\section{REFERENCES}

1. ATSDR, Toxicology profile for polyaromatic hydrocarbons. ATSDR's Toxicological Profiles on CD-ROM, CRC Press, Boca Raton, FL, 2005.

2. L. Keith, Polycylic Aromatic. Compounds., 2014, 35, 147.

3. J.H. Rodriguez, E.D. Wannaz, M.J. Salazar, M.L. Pignata, A. Fangmeier, J. Franzaring, Journal of Atmospheric Environment, 2012, 55, 35.

4. H.I. Abdel-Shafy, M.S.M. Mansour, Egyptian Journal of Petroleum, 2016, 25, 107.

5. Katsoyiannis, E. Terzi, Q.-Y. Cai, Chemosphere, 2007, 69, 1337.

6. Oliveira, N. Martins, J. Tavares, C. Pio, M. Cerqueira, M. Matos, H. Silva, C. Oliveira, F. Camőes, Chemosphere, 2011, 83, 1588.

7. W. Zhang, S. Zhang, C. Wan, D. Yue, Y. Ye, X. Wang, Environmental Pollution, 2008, 153, 594.

8. M.B. Yunker, R.W. Macdonald, R. Vingarzan, R.H. Mitchell, D. Goyette, S. Sylvestre, Organic Geochemistry, 2002, 33, 489.

9. IARC, Chemical, Environmental and Experimental Data, Part 1, 1983, vol. 32.

10. K. Ravindra, R. Sokhi, R.V. Grieken, Journal of Atmospheric Environment, 2008, 42, 2895.

11. EPRI (Electric Power Research Institute). Literature review of background polycyclic aromatic hydrocarbons. Final report; March 2000.

12. W. Thomas, Journal of Ecotoxicology and Environmental Safety, 1986, 11, 339.

13. E.-L. Viskari, R. Rekilä, S. Roy, O. Lehto, J. Ruuskanen, L. Kärenlampi, Journal of Environmental Pollution, 1997, 97, 153.

14. H.G. Zechmeister, S. Dullinger, D. Hohenwallner, A. Riss, A. Hanus-Illnar, S. Scharf, Environmental Science and Pollution Research, 2006, 13, 398.

15. F. Capozzi, S. Giordano, A. Di Palma, V. Spagnuolo, F. De Nicola, P. Adamo, Chemosphere, 2016, 149, 211.

16. L. Foan, V. Simon, Journal of Chromatography A, 2012, 1256, 22.

17. H. Harmens, L. Foan, V. Simon, G. Mills, Environmental Pollution, 2013, 173, 245.

18. European Union, 2004. Directive 2004/107/EC of the European Parliament and of the Council of 15 December 2004 relating to arsenic, cadmium, mercury, nickel and polycyclic aromatic hydrocarbons in ambient air. Official Journal 23, 3-16.

19. M. Tobiszewski, J. Namiejnik, Environmental Pollution, 2012, 162, 110. 